\title{
Enhancing The Sheltered Instruction Observation Protocol (SIOP) Model with technology for developing secondary school teachers' effective teaching skills and their students' English language achievement
}

\section{Prepared by \\ Hanaa Elsayed Imam Ali}

A lecturer at instruction and curriculum dept.

Faculty of education New valley university

\begin{abstract}
The present research aimed at investigating the effectiveness of enhancing the SIOP model with technology for developing secondary school EFL teachers' effective teaching skills and language achievement of first year secondary school students. The research followed the quasi experimental design. It included two samples; the first was (20) first year secondary school teachers which participated as an experimental group. The other sample was 80 first year secondary school students who were divided into two equivalent groups; 90 students participated in a control group, the other 90 students participated as an experimental group. Materials of the research consisted of the SIOP model enhanced with technology, a training program for teachers based on the SIOP model enhanced with technology. Instruments of the research consisted of an effective teaching observation sheet and language achievement test. Results of the study revealed the high degree of effectiveness of the modified SIOP model enhanced with technology on both secondary school EFL teachers' effective teaching skills and students' language achievement.
\end{abstract}

\section{Keywords}

SIOP model- technology- effective teaching skills- language achievement 


\section{تعريز نهموذج SIOP بالتكنهولوجيا لتنـهية همارات التدريس الفعال لدي

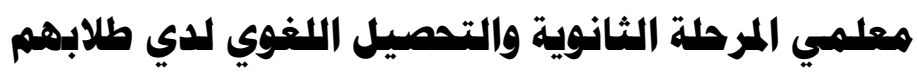 إعداد

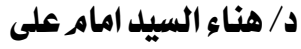 ملدرس بقسم المناهج وطرق التدريس كلية التربية - جامعة الوادى الجديل}

المستخلص - | (المس

يهدف البحث الحالي إلى التحقق من فاعلية تعزيز نموذج SIOP بالثكنولوجيا لتطوير مهار ات التذريس الفعال لمعلمي اللغة الاتجليزية للصف الاول الثانوي و التحصيل اللغوي لاى طلابهم. تبع البحث التصميم شبه التجريبي . وشمل البحث عينتين؛ الأولى تضمنت (·r) معلما من معلمي اللغة الانجليزية للصف الاول الثانوي التي شاركت كمجموعة تجريبية. وتكونت العينة الأخرى من ـ11 طالبا من طلاب الصف الاول الثانوي و تم تقسيمها إلى مجموعتين منكافئتين؛ حيث شارك و طالبا في المجموعة الضابطة، وشارك و طالبا اخرين كمجموعة تجريبية. تتألف مواد البحث من نموذج المعزز بالتكنولوجيا، برنامج تدريبي للمعلمين قائم على نموذج SIOP المعزز بالتكنولوجيا. وتتألف أدوات البحث من بطاقة ملاحظة مهار ات التدريس الفعال واختبار التحصيل اللغوي القبلي بعدي. و كثفت نثائج الدر اسة عن وجود درجة عالية من الفعالية لاستخدام نموذج SIOP المعزز بالتكنولوجيا في تطوير كل من مهارات الثدريس الفعال لدى معلمي اللغة الانجليزية للصف الاول الثانوي وكذلك التحصيل اللغوي لدى دلى طلابهم

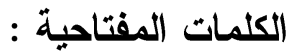
، مهارات التدريس الفعال ، التحصيل اللغوي ، التكنولوجيا SIOP نموذج 


\section{Introduction}

English is the common used foreign language in Egyptian schools. It is a highly valued language to the extent that it was introduced as a mandatory subject from first year primary to the final year in the secondary stage. This importance needs a continuous improvement and progress either in the EFL curriculum or teachers skills and qualifications. Accordingly, there is a growing demand for knowledgeable, skillful, and effective EFL teachers who is provided with the appropriate tools and strategies to meet student needs in the $21^{\text {st }}$ century.

Lopez et al. (2013) report that only thirty percent of all teachers have had professional development experiences addressing English language learners needs and issues. Fillmore and Snow (2010) affirm the need of in- service and prospective teachers to develop their knowledge and skills. Ertmer and Leftwich (2010) and Noll (2013: 404) asserted the English language teachers' need for additional training to increase their knowledge, skills, and understanding in designing and delivering effective instruction for students in the classroom. Brown (2019) mentions that EFL teachers should trained on effective strategies that promote interactive learning.

Also, Hatle (2019) adds that to be successful and to meet the distinct needs of their students, effective teachers need to have a vast repertoire of teaching models and strategies to utilize in their classrooms. Young et al. (2014) stated "For students at the elementary and secondary school levels, access to teachers who have the necessary professional knowledge and functional English language skills to teach English effectively is critical". Thus, training in service teachers on modern and appropriate instructional practices to ensure that all learners are learning were recommended by many researchers. EFL teachers also need to train on making content comprehensible through using innovative tools and materials" (p. 1) 
Moreover, effective teachers impact greatly on their students' achievement. Doherty \& Jacobs (2013) point out that "The metric for teacher effectiveness is student achievement. Cohen and Goldhaber (2016: 380) add that there are multiple dimensions by which a teacher might be deemed effective. The most important is supporting student learning on academic outcomes. Palardy and Rumberger (2008) examined three dimensions of teacher effectiveness - instructional practices, teacher attributes in relation to learning among students. Results revealed that highly instructional practice had the most direct impact on student achievement. More studies as (Baker et al. 2014; Bunch, 2014; Brown , 2019; Gándara and Santibañez, 2016; Johnson and Wells, 2017; Li Nan, 2013; Trickett et al. 2012; van Lier \& Walqui, 2012) proved that teachers needed quality skills, training, or professional development to teach ELL students. Thus the need for skillful and experienced teachers that could cope with the demands of the $21^{\text {st }}$ century is very important for the reform of any educational institution.

For the status quo of teaching English in Egyptian schools, Acquiring English is a difficult issue especially among EFL learners. Studies as (AbdelHafez, 2010; Abdel-Latif , 2012;Ahmad, 2010; McIlwraith and Fortune, 2016; Khalil and Ali, 2018) summarize the challenges of educational reform in Egypt, the most important of them is teaching style and the mismatch between teacher purposes and students' expectations and needs.

Consequently, to meet the needs of developing successful teaching practice, it is urgent to seek some new training models. One of these models is SIOP model of teaching. The Sheltered Instruction Observation Protocol (SIOP) Model is a lesson - planning and delivery approach composed of 30 instructional strategies grouped into eight components: preparation, building background, comprehensible input, strategies, interaction, practice/application, lesson delivery, and review/assessment (Kareva and Echevarria, 2013). It offers a way for teachers to teach content by using strategies and techniques that make new information understandable to students. While doing so, students develop language skills across the domains of reading, writing, listening, and speaking. 
Calderon (2012) asserts that "the SIOP model has all the ingredients needed to help teachers in their task of teaching all students. It can enhance and expand teachers' instructional practice. Also, it promotes, in particular, strategies for improved teacher development and instructional practice " (p.61). Short et al. (2012) mention that "The effectiveness of the SIOP Model, especially in content areas, is foreshadowed in the fact that it teaches content curriculum to students learning through a new language. Teachers employ techniques that make the concepts of the content accessible and develop students' skills in the new language" (p. 334).

Based on the outcomes of all the studies conducted, the implementation of the SIOP Model showed a significant improvement in the EFL classroom in. It has also an impact on the teachers' performance and their quality of teaching, (Boughoulid, 2020; Short, Fidelman, and Louguit, 2012; Short \& Himmel, 2013; Echivarria, Vogt, \& Short 2017; Echivarria and Short, 2016; Chandler, 2020).

To sum up, the SIOP model is an instructional guide for effective teaching, as it provides teachers with organized procedures for presenting language content. Enriching the SIOP model with more resources of technology could enhance language learning outcomes. To enhance SIOP model effectiveness in teaching EFL, the researcher suggested the integration of using technology in each step of the model. The new era demands the technical teacher who could cope with the changes and technological progress that invade the learning teaching environment. As Charalambos and Mcisaac (2010) argued, technology drives reform in education, but also 'education reform makes a school ripe for technology'. Qoura (2017: 186) explains that to keep abreast of the needs and abilities of the ICT age, there is a need to recruit, reward, train, learn from, and honor a new generation of talented teachers.

Many researchers have affirmed the effective contributions of integrating technology into teaching and learning EFL Polyakova, 2020; Habibullaevna, 2020; Sadikin \&Handay, 2019; Pasternak, 2019). Based on the importance of integrating technology in teaching English as a foreign language and responding to the demands of the new century in accordance to the new qualifications and skills of 
teachers in the $21^{\text {st }}$ century, the researcher has enhanced the SIOP model of teaching with technology in order to enhance secondary school teachers' teaching skills and examine its effectiveness on students' language achievement

\section{Context of the Problem}

Teaching practice is an important element of the teacher's professional preparation and development, pre service and in service. There should be a continuous development based on the new changes in methodology and educational technology. According to the new system adopted by the present minister of education, teaching based on technology is the focus of their attention and the essence of development and success. The new system needs a technological qualified teacher who could vary in teaching resources and integrate in class and outclass activities. Although, First year secondary school students do most of learning activities using Tablets, the researcher observed through supervising on practical education groups in secondary schools that teachers lack the technical knowledge to guide students to practice or involve in E- activities. The traditional method was adopted all time. The plan for EFL lessons were unorganized and was a copy of the traditional Teacher's Guide. Resources used in the class were limited to textbook and some demonstrations on the blackboard.

Reviewing first year secondary school students' final results, the statistics showed that $27 \%$ of students had got scores from 40 t0 60 in EFL subject. $35 \%$ had scores from 40 to 30 , the rest of students had failed to achieve success. To investigate the present problem, the researcher conducted four visits to each secondary school in Elkarga city. Moreover, the researcher has organized interviews with a sample of first year secondary school students in each school and some of their supervisors. The result of the visits and the interview indicated that the main factor, that affect students' success in English, was the teacher's style of teaching. Teachers affirmed that their ability to integrate technology in teaching is limited, they need more training on using new methods of teaching that are enhanced with technology, they lack the ability of communicating with students using various social media, and the ability of designing E- tests and E- portfolio.

\section{1}


Thus, the problem of the present research lies in the low level of EFL secondary school teachers in their teaching practices that affects on the achievement of EFL learning objectives and hinders first year secondary school students' language achievement. As well, the new system of secondary school education seeks to integrate technology in all aspects of education. The present study was an attempt to investigate the effectiveness of integrating technology in the SIOP Model in improving EFL teachers' effective teaching skills.

\section{Questions of the study}

The study attempted to answer the following questions:

1. What are the components of the modified SIOP model integrated with technology

2. What is the effectiveness of using a training program based on enhanced with technology into the SIOP model in developing EFL secondary school teachers' effective teaching skills?

3. What is the effectiveness of using the modified SIOP model enhanced with technology in developing first year secondary school students' language achievement

\section{Hypotheses of the study}

The present study tested the following hypotheses:

a) There is a statistically significant difference between the mean scores of the experimental teacher group trained in the modified SIOP model enhanced with technology in the pre and post application of the effective teaching skills observation sheet (in favor of the post application).

b) There is a statistically significant difference between the mean scores of the experimental student group in the pre and post language achievement test (in favor of the post application).

c) There is a statistical significant difference between the experimental and the control groups of first year secondary school students in the language achievement test, (in favour of the experimental student group) 


\section{Purpose of the study}

The present study aimed at:

1. Modifying the SIOP model by integrating technology.

2. Investigating the effectiveness of a training program based on integrating technology into the SIOP model in developping EFL secondary school teachers' effective teaching skills.

3. Detecting the effect of using the modified SIOP model enhanced with technology in developing first year secondary school students' language achievement

\section{Significance of the Study}

The present study was expected to be important as it may:

1. develop EFL teachers' teaching practices and performance as it train them on specific and organized steps and procedures for teaching in EFL classes either in online or face to face environment

2. increase first year secondary school students' language achievement as the teachers' use of SIOP model may provide students with various opportunities to practice language skills interdependently and enhance students' interaction

3. pay the attention of educators and researchers to integrate technology in various teaching models.

4. guide curriculum designers in considering the SIOP Model as one of the successful models for both teachers' development and students' achievement..

\section{Delimitations of the study}

The present study was delimited to:

1. Twenty teachers who were selected to participate in this study.

2. 180 first year secondary school students

3. The third and Fourth units of first year secondary school text book New Hello English- first term of the academic year 2020- 2021 
4. The following effective teaching skills:

- Instructional planning

- Instructional delivery

- Assessment skills

- Developing thinking skills

- Managing learning environment

- Technological skills

\section{Materials and instruments of the study}

The researcher developed and used the following materials and instruments:

- List of effective teaching skills needed for secondary school teachers

- A training program based on the modified Siop model enhanced with technology

- Effective teaching skills observation sheet.

- Language achievement test.

\section{Definition of Terms}

\section{The Sheltered Instruction Observation Protocol (SIOP) Model}

The current study defines the SIOP Model as an instructional method composed of 30 strategies and instructional techniques grouped into eight interrelated components: preparation, building background, comprehensible input, strategies, interaction, practice and application, lesson delivery, and review and assessment.

\section{The modified SIOP model}

The modified SIOP model is a restructured form of the original SIOP model that was enhanced with technology to help eachers increase heir ability of implementing technological intervention and instruments in teaching EFL effectively

\section{Effective teaching skills}

It is a style of teaching aims at achieving the learning using varied innovations and materials and effective methods of teaching.It makes the learner a main focus, a participant and a searcher of information by all possible means, an employee an integrated, creative and innovative. It seeks to create a positive and encouraging learning environment 


\section{Review of Literature}

The Sheltered Instruction Observation Protocol (SIOP) Model

\section{Features of the SIOP model}

The SIOP model is a framework for organizing instruction that train teachers on promoting students' engagement and participation in the process of language learning. It is an an instructional and observational instrument developed as a rating scale. Echevarria et al. ( 2017) explained that the SIOP model serves as the a lesson planning and delivery system and as the Protocol serves to observe, rate and provide feedback on the lessons.

Additionally, Sheltered instruction gives students an opportunity to learn the target language as they master important content and skills. Boughoulid (2020) stated that teachers recognize that students are learning a new language and they make adjustments in lesson planning and delivery to facilitate students' learning. "Sheltered instruction is not a watered-down version of grade level instruction, but is a means for making cognitively challenging lessons comprehensible to second language learners" (Echevarria\& Graves, 2015). The SIOP Model is intended to be applicable at levels of education from pre-K through community college. The instructional features address the academic and linguistic needs of English learners and all students who are learning content through a second language (Short \& Himmel, 2013).

SIOP classes are student-centered and welcoming where English learners have opportunities to use language in authentic ways, collaborating with peers around grade-level concepts and information, practicing and applying the material to meet the lesson's objectives (Short and Himmel, 2013). The model is not an add-on responsibility for teachers, but rather a planning framework that ensures effective practices are implemented to benefit all learners (Echevarria, Vogt and Short, 2017). Additionally, SIOP provides teachers with a coherent approach for planning and delivering relevant, meaningful lessons that provide ample opportunities for students to interact with one around content concepts aligned to state and national standards (Echevarria and Graves, 2015).

\section{5}


To sum up, Sheltered Instruction is a way of teaching that makes lessons meaningful and understandable for second language learners. The goal of sheltered instruction is to provide access to the core curriculum by teaching in a way that is meaningful and understandable for second language learners and through these modified lessons, students learn language domains interdependently.

\section{Components of the SIOP model}

The SIOP Model is organized in eight components. Echevarría, et al. (2017) pointed out that "The components and features of the SIOP Model are interrelated and integrated into each and every lesson. these eight components comprise the three steps of teaching: lesson preparation, instruction, and review/assessment" (p. 167) . Prabjandee (2016) explains that the components of SIOP are often misinterpreted as a step-by-step process. Naturally, teachers need to plan first before carrying out lessons; however, it is possible, and even recommended, that teachers review and assess knowledge at the start of the lesson and throughout, not only as the last component.

Each of the eight components has indicators that the teacher can refer to when ensuring that the lesson will adequately make the content comprehensible for English learners. Each component has a rubric called the Protocol that is used by teachers and administrators to measure how well the lesson adheres to the certain component. According to Echevarria, Vogt \& Short ( 2017), Prabjandee (2016), Read (2008), the SIop model components are as follows:

Lesson Preparation

Each SIOP lesson has content and language objectives that are clearly defined, displayed, and orally reviewed with students. For teachers, the goal is to help students gain important experience with key grade-level content and skills as they progress toward fluency in academic English. Adaptations are provided through a number of ways, such as differentiated texts, supportive handouts, and audio selections. Also, meaningful activities must be planned to provide access to the key concepts and provide opportunities for students to apply their content and language learning. 


\section{Building Background}

In SIOP lessons, teachers help students connect new concepts with their personal and cultural experiences and past learning. Teachers sometimes build background knowledge. At other times, teachers activate students' prior knowledge to tap into what students already know, to identify misinformation, or to discover when it's necessary to fill in gaps.

\section{Comprehensible Input}

SIOP lesson includes a variety of SIOP techniques so students comprehend the lesson's key concepts. Examples of language accommodation techniques include teacher talk that is appropriate to student proficiency levels; restatement; paraphrasing; repetition; written records of key points; and previews and reviews of important information. Further, teachers explain the academic tasks they expect students to perform, orally and in writing, with demonstrations, modeling, and sample products as needed.

\section{Strategies}

This SIOP component addresses student learning strategies, teacher-scaffolded instruction, and higher-order thinking skills. Some students aren't familiar with learning strategies and benefit from learning how to use them flexibly and in combination. SIOP teachers frequently scaffold instruction (provide support, as needed) so second language students can be successful with academic tasks. As English learners master a skill or task, teachers remove supports that were provided, and add new ones for higher levels of application. SIOP teachers also ask English learners a range of questions, many of which require higher levels of thinking, thus going beyond questions that can be answered with a one- or two-word response. Instead, they ask questions and create projects or tasks that require students to think more critically and apply their language skills in more extended ways. Students' answers may contain few words but the goal is for those words to represent complex thinking.

\section{7}




\section{Interaction}

Students learn both conversational and academic language through interaction with one another and with their teachers. However, it is academic proficiency that is associated with school success. In SIOP classes, oral language practice helps students develop and deepen content knowledge, and it supports their second language listening, speaking, reading, and writing skills. In pairs and small groups, second language learners practice new language structures and vocabulary that they have learned, as well as important language functions, such as asking for clarification, confirming interpretations, elaborating on one's own or another's idea, citing evidence in the text to support claims, and evaluating opinions. Opportunities for oral language practice are especially important since oral language proficiency impacts all aspects of educational achievement.

\section{Practice \& Application}

For second language learners to learn the target language, it is imperative that every lesson provides opportunities for them to practice and apply content information, as well as literacy and language processes (i.e., reading, writing, listening and speaking).

\section{Lesson Delivery}

SIOP teachers introduce (and revisit) meaningful activities that appeal to students, they provide appropriate wait time so students can process concepts, and the classroom instruction fosters high motivation and engagement.

\section{Review \& Assessment}

As part of each SIOP lesson, teachers make time for review and assessment throughout a lesson. In fact, a lesson may begin with a review of previous learning or a check of students' knowledge of a topic. SIOP teachers check on student comprehension frequently to determine whether additional explanations or re-teaching are needed. By doing so, they can also provide feedback on correct and incorrect responses, a practice shown to benefit second language learners. 
Based on the previous review of literature, it is noted that The SIOP model is an eight step model that gives teachers the tools to implement content language teaching effectively. The SIOP Model includes features of high quality instruction for all students, such as the inclusion of language objectives in every lesson, the development of background knowledge, the acquisition of content-related vocabulary, and the emphasis on assessment techniques. The SIOP model is considered a consistent teaching method in which peers can observe and coach each other in classrooms.

The important aspect of SIOP is consistently developing academic language domains regularly as part of the content lessons and units that are planned and delivered. The implementation of the SIOP model permits variation in classroom practices; however, when consistently implemented, it shows the way to improve teaching practices in EFL classrooms.

\section{Advantages and Benefits of the SIOP Model:}

Through this protocol, teachers could plan, implement, and observe good quality lessons built mainly on the students' different ways of learning to meet their needs and interests in terms of their English language proficiency. "The SIOP Model provides teachers with ample models to deliver and implement lessons in an anxietyfree atmosphere where every student is enjoying the class activities" (Mesquita, 2009, P. 8).

Through the SIOP model, teachers are encouraged to modify their ways of teaching. At the same time, this method gives broader opportunities for the learners to interact with their classmates and strengthen their use of the English language in both content and language areas (Short, Fidelman, \& Louguit, 2012, p.348)..

Echevarria \& Short (2016) emphasize that "By conscientiously sheltering instruction through strategy teaching and modeling, by appropriately scaffolding support, and by thoughtfully asking questions that require students to interpret, apply, and synthesize, we increase the chances that English learners will become critical thinkers" (p. 97). 
The SIOP Model directs the lessons where students are constantly engaged and interacting with the teacher, with their classmates, and with text, which leads to elaborated discourse and critical thinking, and consequently promotes language acquisition (Echevarría, Vogt, \& Short, 2017, p. 17). According to Vogt et al. ( 2010), language skills of listening, speaking, reading and writing develop interdependently; therefore, effective lessons that increase opportunities for ELL students to access content must include multiple opportunities for students to engage in these academic language-learning behaviors

Many studies have revealed the positive impact of SIOP model in language learning and teaching; Miner (2006) reported significant differences between treatment and control groups in the areas of reading and mathematics in grades 3, 4, and 5. Read (2008) conducted a study to examine the impact of SIOP training on the instructional practices of 26 teachers and the achievement of ELLs in reading for grade 3-5 students. Moux (2010) conducted a qualitative case study to explore the use of SIOP instructional practices to promote the language development and learning of elementary English language learners (ELLs) in an immersion setting in 1st and 2nd grades. Molitor (2012) examined the impact of instructional models on the implementation of effective ELL practices. Ebedy (2019) conducted a study aimed at developing reading comprehension skills using Sheltered Instruction Observation Protocol (SIOP) among second-year English majors at the Faculty of Foreign Languages and Translation, Misr University for Science and Technology. The findings of the study showed that the experimental group students outperformed the control group students in reading comprehension skills.

Basically, the present study aimed at investigating the effectiveness of the SIOP model enhanced with technology in developing teachers' effective teaching skills and language achievement of their students when they were instructed EFL using the modified SIOP model 


\section{Integrating technology into the SIOP model}

In light of the requirements of the era of science and knowledge and the tremendous transformation in information and communication technology, the teacher is no longer the only source of knowledge. There are many sources of knowledge and methods of obtaining knowledge. The role of the teacher as mediator and facilitator between the students and sources of knowledge became dominant recently. The teacher is the decisive factor in the effectiveness of the teaching process, who organizes the experiences and manages them and implemented them in the direction of specific learning objectives; it is no longer limited to provide the learner different kinds of knowledge and fill in memory.

Training in service teachers on using technology while designing activities for their students accommodates the demands of the new era and the revolution of technology in recent years. So, it is better to include new traiing programs that qualified teachers to cope with recent changes in technology and knowledge. Cavanaugh (2009) stated "universities and teacher education institutions in higher education need to include literacy and technology concepts and address new ICTs (Information and Communication Technologies)". He recommended that teacher educators should integrate effective instructional models, using the Internet into preparation programs to provide opportunities for pre-service teachers to practice by using age-appropriate ICTs.

Motteram (2013) claimed "Instructors/designers must continue to design activities that support learning objectives, but structure them to work online, outside of the traditional classroom environment where active learning techniques are heavily dependent upon face to- face interaction (e.g., Discussion, group work, and role-play" (p. 28).

Enhancing the SIOP model with technology might increase its effectiveness in an era depends on integrating technology in each aspect of the learning process. The National Educational Technology Standards (NETS) for Teachers (ISTE, 2000) assure the role of 
technology for in the teaching and learning process. The standards are as follows:

1. Teachers demonstrate a sound understanding of technology operations and concepts.

2. Teachers plan and design effective learning environments and experiences supported by technology.

3. Teachers implement curriculum plans that include methods and strategies for applying technology to maximize student learning.

4. Teachers apply technology to facilitate a variety of effective assessment and evaluation strategies.

5. Teachers use technology to enhance their productivity and professional practice.

6. Teachers understand the social, ethical, legal, and human issues surrounding the use of technology in PK-12 schools and apply those principles in practice.

\section{Effective teaching skills}

\section{The process of Teaching}

One of the important factors of teachers' success in his profession is the acquisition and practice of teaching skills. Hameeda (2013) defines teaching as the set of teaching activities and processes performed by the student- teacher within the classroom as he explains courses lessons in the light of international standards to improve the teaching and learning process by using teaching strategies to achieve specific goals" (p. 125).

Akinsola (2014) defines teaching practice as a time when all learned theoretical concepts and ideas in educational psychology, management of classroom, subject content, curriculum development, various philosophies dealing with education are called into use (p. 42).

Naglar (2016) recognizes the teaching as a set of behaviors and teaching practices carried out by the teacher during the implementation of the lessons and is characterized by the accuracy and proficiency of performance, which assessed according to the following areas: (planning of the lesson - implementation of teaching - classroom management and order maintenance - motivation - Class Questions - Personal Semantics and Human Relations - Mastery of Specialization - Teaching and student learning Evaluation (p. 165). 


\section{Effective teaching skills}

Teaching in general represents the activities and procedures that teachers manage in order to achieve the objectives of learning, Teaching effectiveness on the other hand is well the teaching process was done through the use of appropriate pedagogy, learner and teacher engagement in the lesson, appropriate use of learning materials, feedback from learners etc. it is the evaluation of teaching and learning in the classroom. Teaching effectiveness is a measure of process; The process of designing and understanding the need of the students. By designing and implementing the process properly the result will reach a real effective stage.

More focusly, Effective teaching can be defined by (Al-Ali, 2009) as "a pattern of teaching that depends on the self activity and positive participation of the learners, through which they may search using a range of activities and scientific processes such as observation, assumptions, measurement, data reading and deduction, which help them to reach the required information by themselves and under the supervision, guidance and assessment of the teacher.

Ziyoudi (2012) stated that the effective teacher is the one who can use the appropriate teaching method at the appropriate time; effective teaching methods that would increase the motivation of students and giving them different skills and guide them towards the effective active learning away from routine and boredom. Kubaisi (2009) pointed that an educationally successful teacher is the one that optimizes the use of efficient teaching aids and modern technology.

Ferjani (2002) confirmed the importance of the use of teaching aids in the educational field, where using these aids has become an urgent necessity for various educational situations that resulted in the quality ofeducational outcomes. Teaching aids help students acquire experience, increase positive participation, change behavior, form new trends and sound concepts, avoid verbal mistakes, and consolidate and deepen the learning process (Salama, 2004). Teaching aids stimulate effective teaching methods through cooperation and participation, problem solving, discussion, notes, and other strategies and techniques that reinforce students to easily learn the lesson - depending on the teacher's role in the activation process. 
To be effective, the teacher must have effective communication skills that enable him to give clear presentation in a persuasive effective way using verbal and non-verbal communication skills, effective teaching methods, persuasion power, configuring proper learning environment with various communication skills, reinforcing students' skills and understanding, so as to facilitate the learning process and achieve the targeted results (Zayed, 2013).

According to Kim et al. (2019), a measure of 21st century effective teaching behaviors should include being able to solve problems, taking care and managing self, adapting to change, conceptualizing ideas, analyzing and evaluating, communicating and sharing, collaborating with others, and being ready for change.

Rubio (2018) mentions a continuum of behaviors expected to be acquired by student teachers for the planning, implementation and evaluation processes. They are expected to: create safe and effective learning environments, bring in use multiple forms of classroom communication skills and take effective measures in order to organize Students Learning (p. 316).

Welsh and Schaffer (2017) stated the following traits of effective teachers:

- Effective teachers use techniques that best serve the learning needs of their students.

- Effective teachers teach in a way that encourages students to take greater responsibility for their own learning.

- Effective teachers have a thorough knowledge of their subject content and skills.

- Effective teachers provide a safe and orderly environment, both physically and emotionally, so students can achieve their potential.

- Effective teachers closely monitor each student's achievements. This enables them to provide every one of their students with regular feedback on their performance, and gives them valuable information to assess the impact of their teaching

- Effective teachers develop productive relationships with their students - they get to know them and take a particular interest in their overall development and progress. 
Stronge (2017) listed a framework for effective teaching that addresses:

(1) Professional knowledge

(2) Instructional planning

(3) Instructional delivery

(4) Assessment;

(5) Learning environment; and

(6) Professionalism.

Reviewing the previous literature, it could be noted that the role of the effective teacher is highlighted in the use of various teaching aids and effective methods of teaching represented in planning, implementation, and evaluation levels in order to motivate the learning and educational process among students, and provide them with different thinking skills and activate the student role in teaching and learning. Effective teachers pose high expectations of students and they help them meet those expectations. Effective teachers work in their classroom, according to their learning styles, providing them with all tools and materials to achieve high degree of academic success.

The present research stated the following skills as the needed for EFL inservice teachers based on the previous review of literature:

- Developing thinking and creativity (implementing teaching procedures that provoke students' thinking and creativity)

- Instructional planning: Prepare cohesive and organized lesson plan

- Instructional delivery, which included all activities and performances that teachers execute in the classroom to achieve learning objectives

- Assessment skills included the teachers' ability to check students' achievement and modify their problems and difficulties.

- Managing Learning environment included the teachers' ability to organize and warm up the learning environment for best teaching practices

- Technological skills 


\section{Method of the research}

\section{The experimental design of the research}

The present research followed the quasi experimental design of experimental and control groups and pre post application of the instruments of the study; the study was applied on two samples; a sample of secondary school teachers (20 first year secondary school teachers) and a sample of (180) first year secondary school students.

\section{Participants}

The sample of the study included 20 inservice teachers who teaching for first year secondary school students. The research group were chosen voluntarily. The sample of the study was selected from fist year secondary school teachers as they need more training on using technology in teaching. New teaching and learning systems in first year secondary stage are depended on using new technological interventions in teaching .

Moreover, the participants of the present research included 180 first year secondary school students who were enrolled in 6 classes and were divided into two groups one as an experimental and the other as a control. Those classes were selected intentionally where the sample of teachers teaches.

The group of the study were distributed as follows:

- The experimental group of secondary school teachers included (20) EFL secondary school teachers who received a training program based on the SIOP model enhanced with technology

- The experimental group included (90) first year secondary school students who was taught the third unit of Hello English using the SIOP model integrated with technology.

- Thecontrol group included (90) first year secondary school students who was taught the third unit of Hello English using the conventional method of teaching 


\section{Instruments and Materials of the research:}

\section{Instruments of the research}

\section{1- Effective teaching observation sheet}

The observation sheet aimed at assessing the secondary school teachers' effective teaching skills. In order to design the observation sheet, the following procedures were followed:

- Depending on the review of literature, the researcher prepared a list of effective teaching skills. The list consisted of $35 \mathrm{sub}$ skills. The list was judged by a panel of jury members specialized in teaching EFL $(n=9)$. They were requested to judge its suitability to the sample of the study of the research. In the light of the jury's suggestions the researcher made the necessary changes and prepared the final form of the list which includes:

1. Instructional planning (10 subskills)

2. Instructional delivery (10 sub skills)

3. Developing thinking and creativity (5 sub skills)

4. Assessment (5 sub skills)

5. Managing Learning environment (5 sub skills)

6. Use of technology (5 sub skills)

- Based on the final form of the effective teaching skills list, the researcher prepared an observation sheet which consisted of 40 items with a scoring scale of three scale points ranging from 0 to 2 . (i.e. $1=$ available poorly $-2=$ available adequately $-3=$ available greatly). The total score of the sheet was (120)

- The reliability of the observation sheet was measured by an inter rater reliability formula . The teachers' performance was recorded and assessed twice; once by the researcher and another by another rater who has the same qualifications of the researchers. Then inter rater reliability was calculated which indicated a high level of reliability.. It was 0.85

- After piloting the observation sheet, it was used as a pre post assessment tool 


\section{2- Language Achievement Test}

- The language achievement test aimed to assess first year secondary school students' achievement in the following criteria :

- language function

- vocabulary and structure

- reading comprehension skills

- some writing skills .

- The test passed through a set of procedures as follows:

- Selecting the third and fourth unit of the first year secondary school textbook " Hello English", the first term of the academic year 2020 - 2021. Each unit consisted of five lesonsTable (1) shows the content analysis of the unit.

- Analyzing the content of units three and four in the light of language skills, vocabulary and structures, and grammer included in the units.

- The content analysis was judged by a group of head teachers and EFL supervisors who reported the validity . To assure the reliability of the content analysis, the researcher analyzed the intended units twice by herself with a month as a breaking time. Coper formula was used to obtain the reliability coefficients. Table (1) shows the reliability values of the content analysis

Table (1)

Reliability values of content analysis

\begin{tabular}{|c|c|c|}
\hline Categories & Agreement coefficient & $\%$ \\
\hline Vocabulary items & 0.99 & 99 \\
\hline Grammatical items & 0.97 & 97 \\
\hline Language functions & 0.95 & 95 \\
\hline Reading and writing skills & 0.98 & 98 \\
\hline Total & 0.99 & 99 \\
\hline
\end{tabular}


- Preparing the language achievement test that included the main language domains involved in the third and fourth unit of the textbook.

- The test consisted of 40 items into four parts :

o The first assesses language function (8 questions)

$\circ$ the second assesses vocabulary and grammar acquisition, (21 questions).

- The third assesses reading comprehension skills (10 questions)and

○ The last assesses some writing skills (one productive question) .

- Each correct answer was given one mark, except the writing question was marked according to a written performance rubric of (10 marks).

- The total score of the test was (49).

\section{Piloting the test :}

- The test was administered to a sample of 35 students to assess its reliability difficulty and discrimination indices

○ Using test re test method, the test reliability was (0.681).

- Difficulty indices were between 0.33 to 0.47

○ Discrimintion indices were between 0.27 to 0.53

o Time of the test is (60) minutes.

\section{Materials of the research}

\section{A. The materials of the research include the following:}

\section{1- The modified SIOP model after integrating technology}

- The content of the modified form of the SIOP model:

The Sheltered Instruction Observation Protocol (SIOP) was developed to make content material more comprehensible to English Language Learners. The model was developed by Jana Echevarria, Mary Ellen Vogt and Deborah J. Short. The original SIOP Model includes the following eight components: table (2) shows the components of the SIOP model 
Table (2)

the components of the original SIOP model

\begin{tabular}{|c|c|}
\hline Components & Items \\
\hline Lesson Preparation & 6 \\
\hline Building Background & 3 \\
\hline Comprehensible Input & 3 \\
\hline Strategies & 3 \\
\hline Interaction & 4 \\
\hline Practice/Application & 3 \\
\hline Lesson Delivery & 4 \\
\hline Review/Assessment & 4 \\
\hline
\end{tabular}

- The modified SIOP model is a restructured form of the original SIOP model that was enhanced with technology, thus, new statements were added and original statements were modified in order to make use of the new technological interventions and creativities in teaching EFL language in secondary school.

- The modified model was targeted to develop EFL teachers' effective teaching skills

Table (3)

The modified SIOP model

\begin{tabular}{|c|c|c|}
\hline Components & Items & The added statments \\
\hline Lesson Preparation & 6 & 5 \\
\hline Building Background & 3 & 4 \\
\hline Comprehensible Input & 3 & 2 \\
\hline Strategies & 3 & 2 \\
\hline Interaction & 4 & 3 \\
\hline Practice/Application & 3 & 2 \\
\hline Lesson Delivery & 4 & 5 \\
\hline Review/Assessment & 4 & 2 \\
\hline
\end{tabular}




\section{- Validity of the modified SIOP model}

To assure the validity of the content of the modified model for EFL teachers, it was judged by a panel of specialists( $n=9)$. They were required to give their points of view in regard to and the suitability of the insuction and activities, resources and content area. The Judges recommended the omission of two statements and the addition of some technological resources in some components of the model. They asserted the creativity and variedness of the designed activities. They all approved its suitability for the subjects and the objectives of the study.

Thus, the modified model in its final form consisted of (55) items distributed into 8 components.

\section{B. The training program based on the modified SIOP model enhanced with technology}

- The modified SIOP model based program aimed at developing secondary school teachers' effective teaching skills through training on the implementation of the modified Siop model in EFL teaching in a way that could increase first year secondary school students' language achievement.

- Building the training program followed the following procedures:

\section{Determining the principles and basics of the training program:}

- The program was built according to the following principles:

- Educational literature and previous studies in the field of effective teaching skills, and the use of SIOP model as a guide in teaching EFL.

○ The professional requirements of the teachers of EFL under the technological developments and requirements of the era of science and knowledge

- Objectives of teaching EFL in secondary school

- the training program objectives were as follows:

$\circ$ Identifying the EFL lesson components according to the SIOP model

○ Including technological tools effectively in lesson plans 
○ Planning for achieving effective EFL objectives in secondary school implementing appropriate teaching procedures

- Planning for better use of technology in the learning and instructional processes inside and outside the classroom

$\circ$ Designing a good learning environment either electronically or in the classroom

○ Design e- activities that directed to achieve the intended objectives of the lesson

- Managing students interaction and participation in online activities

- Identifying the assessment techniques and procedures appropriate for first year secondary school students.

o choosing a variety of suitable methods and tools for evaluating cognitive and behavioral aspects and use them effectively,

- Possessing the suitable educational and management (inservice) experiences for the teaching job in the light of related learning systems.

\section{The content of the suggested program}

- The training program was based on the components of the modified SIOP model of teaching. It composed of 8 modules which should be studied autonomously by the sample of the research with the guide of the trainer. The modules were as follows:

- Lesson Preparation

- Building Background

- Comprehensible Input

- Strategies

- Interaction

○ Practice/Application

○ Lesson Delivery

- Review/Assessment 
- The content of the proposed training program ensures all the knowledge, experience and the skills that the teacher should acquire to use the modified SIOP model in the teaching of EFL for first year secondary school students.

- Every module was studied in four hours, thus,the study of the program required 32 hours. The content of the program was selected and prepared in the light of:

o The relevance of the content to the goals they seek to achieve

- The universality of the modules on all aspects of the expertise and skills required for teachers' development professionally.

o The grading of the activities from easy to hard.

- The individual differences of teachers

o Continuous evaluation.

- Each module included the following contents:

- The title of the module: It reflects the basic idea of the module and the content it contains

o Instructions: The module is based on self-learning, and each teacher follows the steps and instructions specified within each module

- The introduction of the module, which presents a general idea of the importance of the topic of the module, and includes a set of questions that stimulate the motivation of learners to learn the module

○ Objectives to be achieved through studying the model

o pre testing,which is prepared to identify the previous experiences of the student on the topic of the module. The questions in each module vary from right / wrong and multi-choice or open-ended questions depending on the nature of each module

- Each module includes a set of instruction, activities and resources associated with the module title and has been presented as presentations or videos recorded and posted 
on the Google Classroom site where teachers can refer to them at any time and are able to perform the required electronic assignments.

- Additional readings : each module includes a list of references and electronic search sites, which can be consulted for more knowledge and application.

○ Post-test which is a self-assessment test that helps the teachers to verify the level of achievement of the specific procedural goals in each module, and allows the student to move to the next module only after $80 \%$ in the posttest, a picture similar to the test tribal.

- Methods of teaching and educational activities:

In light of the objectives and content of each module, the selection of teaching methods that fit the content and lead to the achievement of the objectives.Oral presentations, online practices, online discussions, group projects and lecturing were used in the program

- Evaluation techniques:

pre post tests, group evaluation and self evaluation techniques were used

- Pioloting the training program:

The program in its initial form was judged by a panel of jury members of technology and TEFL to ensure its validity to the purpose of the study and its appropriateness to the level of the sample.

- Two modules of the program were instructed to elicit the difficulties of the program and the problems that may be appeared during the experiment. 


\section{The experimental Treatment}

\section{Pre testing}

According to the research design, the instruments of the research were applied prior to the implementation of the experiment; two weeks before. Three EFL supervisors were participated in the assessment of the experimental groups using the effective teaching skills observation sheet. They were interviewed with the researcher and were trained to use the observation sheet. The teachers' performance was recorded and evaluated twice at least from the researcher and the supervisors.

For the purpose of the research, 180 first year students were exposed to a language achievement test prior to study the third and fourth unit of New Hello. The student group was divided into two equivalent groups according to heir scores in the pre testing, then a ttest formula was applied o ensure their equivalence

\section{Applying the experimental Treatment}

The experimental group of teachers was instructed through using the training programs for eight weeks; one module a week. The trainers were asked to plan lessons of unit $3 \& 4$ in light of the procedures of the modified SIOP model. Three trainers of the same qualifications and scores on the observation sheet were asked to instruct 90 students enrolled in three classes using the SIOP model of teaching enhanced with technology. The instruction lasted for two weeks; five hours a week, one hour a day.

The other 90 students (control group) were instructed the third and fourth units by three other teachers using the traditional method of teaching. Those teachers did not have any training on the modeified SIOP model; they were selected intentionally as they have the same qualifications and years of experience as the experimental three teachers.

\section{Post testing}

Post instruments were applied after finishing the instruction of the program.

\section{5}




\section{Results}

\section{Findings and Discussions}

The Wilcoxon Signed Ranks Test and t-test was used to compare the pre and post performance of the experimental groups and the post testing of the control and experimental groups to find out the degree of improvement in their effective teaching skills and its effectiveness on their students language achievement level. The results of the comparison revealed a high degree of improvement in favor of the post performance of the research instruments and the excellence of the experimental teacher group and their students' language acheivement.

\section{Testing hypothesis one}

Hypothesis one predicted a statistically significant difference between the means of the teachers' scores on the pre-post observation sheet of effective teaching skills favoring the post application. Table (4) showsWilcoxon Signed Ranks test results of pre-post testing of the experimental group's effective teaching skills

Table (4)

Wilcoxon Signed Ranks Test Results of the teachers on the Pre-post observation sheet of effective teaching skills

\begin{tabular}{|c|c|c|c|c|c|c|c|}
\hline & Administration & No. & $\begin{array}{c}\text { Mean } \\
\text { rank }\end{array}$ & $\begin{array}{c}\text { Sum of } \\
\text { ranks }\end{array}$ & "z" & Sig. & ${ }^{2} \eta$ \\
\hline \multirow{2}{*}{$\begin{array}{l}\text { Instructional } \\
\text { Planning }\end{array}$} & Pre & \multirow[b]{2}{*}{20} & \multirow[b]{2}{*}{10.50} & \multirow[b]{2}{*}{210} & \multirow[b]{2}{*}{3.931} & \multirow[b]{2}{*}{0.01} & \multirow{2}{*}{$0 . \dot{9} 25$} \\
\hline & Post & & & & & & \\
\hline \multirow{2}{*}{$\begin{array}{c}\text { Instructional } \\
\text { delivery }\end{array}$} & Pre & \multirow{2}{*}{20} & \multirow{2}{*}{10.50} & \multirow{2}{*}{210} & \multirow{2}{*}{3.942} & \multirow{2}{*}{0.01} & \multirow[t]{2}{*}{0.983} \\
\hline & Post & & & & & & \\
\hline \multirow{2}{*}{$\begin{array}{l}\text { Assessment } \\
\text { sills }\end{array}$} & Pre & \multirow{2}{*}{20} & \multirow{2}{*}{10.50} & \multirow{2}{*}{210} & \multirow{2}{*}{3.933} & \multirow{2}{*}{0.01} & \multirow{2}{*}{0.847} \\
\hline & Post & & & & & & \\
\hline \multirow{2}{*}{$\begin{array}{l}\text { Developing } \\
\text { thinking and } \\
\text { creativity }\end{array}$} & Pre & \multirow[b]{2}{*}{20} & \multirow[b]{2}{*}{10.50} & \multirow[b]{2}{*}{210} & \multirow[b]{2}{*}{3.942} & \multirow[b]{2}{*}{0.01} & \multirow{2}{*}{0.789} \\
\hline & Post & & & & & & \\
\hline \multirow{2}{*}{$\begin{array}{c}\text { Learning } \\
\text { environment }\end{array}$} & Pre & \multirow{2}{*}{20} & \multirow{2}{*}{10.50} & \multirow{2}{*}{210} & \multirow{2}{*}{3.942} & \multirow{2}{*}{0.01} & \multirow[t]{2}{*}{093} \\
\hline & Post & & & & & & \\
\hline \multirow{2}{*}{$\begin{array}{c}\text { Technological } \\
\text { skills } \\
\end{array}$} & Pre & & \multirow{2}{*}{10.0} & \multirow{2}{*}{210} & 3054 & 001 & 097 \\
\hline & Post & & & & 3.954 & 0.01 & 0.92 \\
\hline Total & Pre & & 1050 & 210 & 3076 & 01 & 008 \\
\hline rotal & Post & & 10.50 & 210 & $3.9<0$ & 0.1 & 0.98 \\
\hline
\end{tabular}


Table (4) shows a comparison of mean scores gained by the experimental teacher group in the pre-post observation sheet of effective teaching skills. The results showed that the participants achieved a high significant degree of improvement in favor of the post performance. Therefore, the first hypothesis is accepted. The table also indicates that the suggested training program based on the modified SIOP model integrated with technology was effective in developing the effective teaching skills of secondary school teachers. The effectiveness of the suggested program was calculated using Etta Squared formula which indicated a high degree of effectiveness (Allam,2000). In addition, the effectiveness value using Blake's formula reveals a high degree of effectiveness as indicated in table (5)

Table (5)

Blank value

\begin{tabular}{|c|c|}
\hline Effective teaching & Blak value \\
\hline Instructional Planning & 1.23 \\
\hline Instructional delivery & 1.30 \\
\hline Assessment sills & 1.23 \\
\hline Developing thinking and creativity & 0.94 \\
\hline Learning environment & 1.40 \\
\hline Technological skills & 1.38 \\
\hline Total & 1.26 \\
\hline
\end{tabular}

Table (5) revealed a high degree of effectiveness of the training program on secondary school teachers' effective teaching skills in whole and in all its subskills.

\section{Testing Hypothesis Two}

Hypothesis two apredicted a statistically significant difference between the means of the first year secondary school students' scores on the pre-post language achievement test (in favor of the post application).

Table (6) shows t-test results of pre-post testing of the students' language acheivement. 


\section{Table (6)}

T-test Results of the experimental student group on the Pre-post Test of language aheivement.

\begin{tabular}{|c|c|c|c|c|c|c|}
\hline Administration & Ss & Mean & S D & "t" & Sig & ${ }^{2} \eta$ \\
\hline Pre & \multirow{2}{*}{90} & 10.14 & 1.99753 & \multirow{2}{*}{99.363} & \multirow{2}{*}{0.01} & \multirow{2}{*}{.0 .982} \\
\hline Post & & 45.9 & 2.768 & & & \\
\hline
\end{tabular}

Table (6) shows that there is a statistically significant difference between the means of the experimental student group scores on the pre-post test of language achievement, that is the students achieved a high significant degree of improvement in favor of the post performance, as " $t$ " value (99.363) is significant at 0.01 level. Thus, the hypothesis two is accepted.

The table also indicates that the teaching with the modified siop model integrated with technology was effective in developing the students' language acheivement level; as the value of etta was (0.982) which is an acceptable value. In addition, the effectiveness value using Blake's formula was (1.65) which reveals a high degree of effectiveness

\section{Testing Hypothesis Three}

Hypothesis three predicted a statistically significant differences between the means of the experimental and control student groups' scores in the post language achievement test (in favor of the experimental group).

Table (7) shows t-test results of both experimental and controlstudent groups in the language achievement post test.

\section{Table (7)}

T-test Results of the experimental and control student groups on the post Test of language ahievement.

\begin{tabular}{|c|c|c|c|c|c|c|}
\hline Administration & Ss & Mean & S D & "t" & Sig & ${ }^{2} \boldsymbol{\eta}$ \\
\cline { 1 - 5 } Control & \multirow{2}{*}{178} & 16.3333 & 2.89129 & \multirow{2}{*}{70.072} & 0.01 & 0.965 \\
\cline { 1 - 1 } experimental & & 45.9000 & 2.76840 & & \\
\hline
\end{tabular}


Table (7) shows that there is a statistically significant difference between the means of scores of the experimental and control student groups on the post test of language achievement. Thus, hypothesis three is accepted. The table also indicates that the teaching with the modified siop model enhanced with technology was effective in developing the students' language acheivement level; as the value of etta was (0.965) which is an acceptable value.

\section{Discussions}

The present research investigated the effectiveness of training first year secondary school teachers on the SIOP model enhanced with technology in developing their effective teaching skills and the effectiveness of teaching EFL for secondary school students using this instructional model on developing students' language achievement.

Findings of the research were encouraging as they showed that there were statistically significant differences between the mean scores of the experimental teacher group in the pre-post observation sheet of effective teaching skills in favor of the post test. This indicates that the experimental teacher group's effective teaching skills included in the program have been developed.

Additionally, the results of the experimental student group shawed showed a highly degree of improvement in their language achievement; as there was a statistically significant difference between the mean scores of the experimental student group in the prepost language acievment pre post test in favor of the post test. As well, there were statistically significant differences between the means of scores of the experimental and control student groups in favor of the experimental student group.

The results obtained in the pre testing of effective teaching revealed the teachers low level of performance in the target skills specially technological skills. Teachers showed inability in using technological tools either in planning or in implementing the lesson. Their performance lacked organization and the logical and regular sequence of teaching procedures while teaching. Learning

\section{9}


environment lost enthusiasm and encouragment. Teachers main focus was on explaining vocabulary included in the reading text. Independent practices were neglected in implementing the lesson.

The students' scores in the pre-test of language achievement were unsatisfactory. Before implementing the program, the sample of the research showed low level in their language acheivment as they, in the pre testing, showed low level in vocabulary selection, answering reading comprehension and writing questions, and a moderate level in answering grammar and vocabulary acquisition questions. Therefore, when they studied the program, they had an opportunity to practice language skills interdependently, they have an opportunity to listen to models of language practices. That, in turn, enabled them to get higher scores on the post test of language achievement . this result is in accordance with the results of which indicated the effect of instructing students with the SIOP model in developing reading skills

The results obtained in the pre post test indicated that the participants achieved significant improvement in EFL effective teaching skills after being instructed through the program. That could be due to many reasons. One of these reasons was that training in service teachers on an organize instructional model which provide teachers with adequate knowledge about the systematic teaching procedures and the adequate strategies of teaching in each stage of teaching. Focusing on the target language skills and the presented content is the main focus of Siop model. Additionally, it gave them opportunities to practice teaching in an authentic way and to reflect on the teaching practices introduced. The SIOP program succeeded in providing trainees with enough theoretical bases for evaluating their own and others' teaching performance. Also, students became aware of how a certain lesson is taught and the possible activities to be used in the different stages of any lesson (Grammar, reading, writing, listening or speaking). 
Another reason is the integration of technology in the SIOP model which increases its validity and effectiveness. Training teachers on using new technology and designing E- activities for enhancing the process of learning was very beneficial for teachers' performance. Training on planning for lessons based on various technological resources and the inclusion of online platforms for interaction and communication with students were provided in the training program.

The present research agreed with the results of the studies of Miner (2006); Kulich (2009); Read (2008); Moux (2010); Molitor (2012), boughoulid,(2020); Chandler (2020); Echivarria and Short (2016) which showed that the SIOP model has positive effects in promoting teachers performance and students' learning of EFL .

\section{Challenges encountered in conducting the research}

The researcher found some challenges while applying the program such as:

1. The insufficiency of time allotted to the implementation process.

2. Most of the teachers lack enough time to participate in the implementation process.

\section{Recommendations}

Based on the findings of the research, it has become clear that enhancing SIOP model with technology had a statistically significant effect on enhancing the in service EFL teachers' effective teaching skills and students language achievement . Based on the results of the research, the following recommendations were made:

1. training inservice teachers on using new technological tools while teaching

2. including the effective teaching skills in professional preparation programs of teacher either inservice or preservice.

3. Newer methods, Models techniques and strategies should be adopted to encourage the involvement of learners into their learning.

\section{1}




\section{References}

Abdelhafez, A. (2010). An Investigation into Professional Practical Knowledge of EFL Experienced Teachers in Egypt: Implications for Pre-service and In-service Teacher Learning. PhD Dissertation, university of Exeter.

Abdel-Latif, M. (2012). Teaching a standard-based communicative English textbook series to secondary school students in Egypt: Investigating teachers' practices and beliefs. English Teaching, 11(3), 78 .

Ahmed, A. H. (2010). The EFL Essay Writing Difficulties of Egyptian Student Teachers of English: Implications for Essay Writing Curriculum and Instruction. Unpublished $\mathrm{PhD}$. University of Exeter.

Akinsola, M. (2014). Assessing Pre-Service Teachers Teaching Anxiety. American Journal of Educational Research, (2): 4144.

Al-Ali, I. (2009). Effective teaching in educational administration. retrieved:

http://www.edutrapedia.illaf.net/arabic/show_article.thtml?id=189

Baker, S., Lesaux, N., Jayanthi, M., Dimino, J., Proctor, C. P., Morris, J., NewmanGonchar, R. (2014). Teaching academic content and literacy to English language learners in elementary and middle school (NCEE 2014-4012). Washington, DC: U.S. Retrieved from the NCEE website: http://ies.ed.gov/wwc/publicationsreviews.aspx

Blazar, D. (2015). Effective teaching in elementary mathematics: Identifying classroom practices that support student achievement. Economics of Education Review, 48, 16-29.

Boughoulid, M. (2020). The SIOP model as an empowering teaching method for English language learners- a study case . European Journal of English Language Teaching , 6 ( 2 ) :45 -53.

Brown, B. K. (2019). Effective Instruction for English Language Learners . Walden University. Walden Dissertations and Doctoral Studies Collection at ScholarWorks 
Bunch, G. C. (2014). Pedagogical language knowledge: Preparing mainstream teachers for English learners in the new standards era. Review of Research in Education, 37(1), 298-341.

Calderón, C. (2012). Factors Affecting the Implementation of Sheltered Instruction Observation Protocols for English Language Learners. Ph.D. Dissertation, Walden University, ProQuest UMI No. 3518977.

Cavanaugh, C. (2009). Research and Practice in K-12 Online Learning: A Review of Open Access Literature. International Review of Research in Open and Distance Learning, 10 ( 1).

Chandler, P. (2020). Implementing The SIOP Model To Support English Language Learners. Ph.D Theses and dissertation, University of New England.

Charalambos, V.\& Mcisaac, M. (2010). Integrating Technology in Teaching and Teacher Education: Implications for Policy and Curriculum Reform. Educational Media International. (38). 127-132.

Cohen, J., \& Goldhaber, D. (2016). Building a more complete understanding of teacher evaluation using classroom observations. Educational Researcher, 45(6), 378-388.

Doherty, K., \& Jacobs, S. (2013). Connect the dots: Using evaluations of teacher effectiveness to inform policy and practice. State of the states. Washington DC: National Council on Teacher Quality.

Douglas, O. B. \& Marilynn, Q. (2017). Relationship between teacher effectiveness and student achievement: an investigation of teacher quality. $\mathrm{Ph}$. D dissertation, Ballstate university, Indiana

Ebedy H. G. (2019). Developing Reading Comprehension Skills Using Sheltered Instruction Observation Protocol ( SIOP) among EFL Students. Journal of Research in Curriculum, Instruction and Educational Technology, 5(2): 194- 210 
Echevarria, J. \& Graves, A. ( 2015). Sheltered Content Instruction: Teaching English Learners with Diverse Abilities. $5^{\text {th }}$ Ed. Pearson publisher.

Echevarria, J. \& Short, D. (2016). Developing Academic Language with the SIOP Model. Pearson publisher.

Echevarria, J., Vogt, E. M. \& Short D. J. (2017). The SIOP Model for Administrators (2e). $2^{\text {nd }}$. Pearson publisher.

Ertmer, A. \& Leftwich, M.(2010). Teacher Technology Change: How

Knowledge, Confidence, Beliefs, and Culture Intersect. JRTE , 42 (3): 255-284

Fagginger A., M., Hickendorff, M., Van Putten, C., Beguin, A., \& Heiser, W. (2016). Multilevel latent class analysis for largescale educational assessment data: Exploring the relation between the curriculum and students' mathematical strategies. Applied Measurement in Education, 29(2), 144-159.

Ferjani, A. (2002). Technology and the development of education. Dar Gharib for publishing.

Fillmore, L. \& Snow, C.. (2010). What Teachers Need to Know About Language. $3^{\text {rd }}$ ed: Routledge

Gándara, P., \& Santibañez, L. (2016). The Teachers Our English Language Learners Need. Educational Leadership, 73(5), 3237

Habibullaevna, D. M. (2020). Modern Strategies And Innovative Technologies In Teaching English Vocabulary. The American Journal of Social Science and Education Innovations. 2 (12): 66- 71

Hattie, J. (2019). Visible learning for teachers: maximizing impact on learning. Routledge.

Ibrahim, M.K. \& Ibrahim, Y.A.. (2017). Communicative English language teaching in Egypt: Classroom practice and challenges. (27): 285-313. 
Ingvarson, L., \& Rowley, G. (2017). Quality assurance in teacher education and outcomes: A study of 17 countries. Educational Researcher, 46(4), 177-193.

Johnson, T., \& Wells, L. (2017). English Language Learner Teacher Effectiveness and the Common Core. Education Policy Analysis Archives, 25(23).

Kareva, I \& Echevarria, J. (2013). Using the SIOP Model for Effective Content Teaching with Second and Foreign Language Learners . Journal of Education and Training Studies, 1(2)

Khalil, S. \& Ali, A. (2018). Exploring EFL Teachers' and Students' Perceptions of Learner Autonomy in Egyptian Technical Schools. International Journal of English Language Education. 6( 1).

Kim, S., Raza, M. \&Seldman, E. (2019). Improving 21st-century teaching skills: The key to effective $21^{\text {st }}$ century learners. Research in comparative and international education, Education, 14(1): 99- 117

Konig, J., \& Kramer, C. (2016). Teacher professional knowledge and classroom management: On the relation of general pedagogical knowledge (GPK) and classroom management expertise (CME). ZDM Mathematics Education, (48), 139-151.

Li, Nan. (2013). Seeking Best Practices and Meeting The Needs Of The English Language Learners: Using Second Language Theories And Integrating Technology In Teaching. Journal of International Education Research. 9 (3).

Lopez, F., Scanlan, M. \& Gundrum, B. (2013). Preparing Teachers of English Language Learners: Empirical Evidence and Policy Implications. Education Policy Analysis Archives. 21. 10.14507/epaa.v21n20.2013.

McIlwraith, H \& Alistair Fortune, A. (2016). English language teaching and learning in Egypt: an insight . British council publications.

\section{5}


Miner, K. (2006). "Fostering Teacher Efficacy for Teaching Elementary English Language Learning Students Using the Sheltered Instruction Observation Protocol and System-level Supports: A Case Study". Ph.D. Dissertation, The university of Oregon, Proquest (UMI No. 3224108).

Molitor, K. ( 2012): "The Impact of Instructional Models on the Implementation of Effective ELL Practices". Ph.D. Dissertation, George Fox University, ProQuest (UMI No. 3515008).

Motteram G. (2013). Innovations in learning technologies for English language teaching. British Council . London, UK www.britishcouncil.org

Moux, S. (Sept, 2010). "Teachers' Perceptions of Sheltered Instruction Observation Protocol for Teaching Young English Language Learners: A Qualitative Case Study" Ph.D. Dissertation, Walden University. ProQuest (UMI No.3398868).

Nagler, S. (2016). Effective Classroom-Management \& Positive Teaching. English Language Teaching;. 9 (1): 163- 173

Noll, J. (2013). Taking Sides: Clashing Views on Educational Issues (13th ed.).New York, Mc Graw-Hill, Inc.

Palardy, G., \& Rumberger, R. (2008). Teacher effectiveness in First Grade: The importance of background qualifications, attitudes, and instructional practices for student learning. Educational Evaluation and Policy Analysis, 30(2), 111-140. doi: $10.3102 / 0162373708317680$

Pasternak, D. L (2019). Integrating Technology in English Language Arts Teacher Education. Routledge

Polyakova, M.D. (2020). Modern pedagogical technologies in teaching English. Trends in the development of sciences and education , 10 (18): 151- 162.

Prabjandee, D. (2016). Sheltered Instruction Observation Protocol (SIOP): Overview, Misconceptions, and Considerations for Implementation. Journal of Education. 27. 1-17. 
Qoura, A. (2017). EFL Teacher Competencies in the ICT age. Journal of Research in Curriculum, Instruction and Educational Technology, 3(5): 127- 150

Read, F. (2008). "The Impact of the Sheltered Instruction Observation Protocol on the Instructional Practices of Elementary School Teacher and on the Reading Achievement of English Language Learners". Ph.D. Dissertation, Wilmington University, UMI No ( 3342830).

Rubio, C. (2018). Effective teachers -Professional and personal skills", en ENSAYOS, Revista de la Facultad de Educación de Albacete, (24): 35- 64

Sadikin, I. \& Handay, R. (2020). Integrating Technology for Teaching English Writing as A Foreign Language in Indonesian Context. Conference: International Conference of Science and Technology for the Internet of Things

Salama, A. (2004). Means of communication and educational technology. ( 5), Amman: Dar El-Fikr for printing and publishing.

Short, D. \& Himmel, J. (2013). Moving research on Sheltered Instruction into curriculum and professional development practice. Paper delivered at AERA, San Francisco, CA.

Short, D. Fidelman, G.\& Louguit, M. (2012). Developing Academic Language in English Language Learners Through Sheltered Instruction. Tesol, 46(2): 334- 361

Stronge, J. H. (2017).Qualities of Effective Teachers, 3rd Edition. $A S C D$

Trickett, E. J., Rukhotskiy, E., Jeong, A., Genkova, A., Oberoi, A., Weinstein, T., \& Delgado,Y. (2012). The kids are terrific: It's the job that's tough: The ELL teacher role in an urban context. Teaching and Teacher Education, 28(2), 283- 292.

Van Lier, L., \& Walqui, A. (2012). Language and the common core state standards. Commissioned Papers on Language and Literacy Issues in the Common Core State Standards and Next 
Generation Science Standards, 94, 44. Retrieved from http://ell.stanford.edu/sites/default/files/pdf/academicpapers/04 Van\%20Lier\%20Walqui\%20Language\%20and\%20CCSS\%20 FINAL.pdf

Wahsheh, R.; Alhawamdeh, H. (2015). The Role of Female Teachers in Activating Effective Teaching Skills and Methods among High School Students from the Teachers' Perspective--Najran, KSA. Journal of Education and Practice, 6 (36 ): 162- 174

Welsh, K. A.; Schaffer, C. (2017). Developing the Effective Teaching Skills of Teacher Candidates during Early Field Experiences. Educational Forum, 81 (3 ): 301-321

Young W, Freeman D, Hauck MC, Garcia Gomez P, and Papageorgiou S (2014) A Design Framework for the ELTeach Program Assessments (ELT Research Report No RR- 13-46). Princeton, NJ: Educational Testing Service.

Zayed, I. (2013). Possible ways to raise the level of skills and abilities of students in the Arabic language. Second International Conference of the Arabic language under the title "the Arabic language is in danger: Everyone must protect it, May 7th to 10th, the University of Al-Zawya, Libya.

Ziyoudi, M. (2012). The role of information and communication technology - project of the development of education towards cognitive economy - in the development of life skills among students of the Jordanian public schools. The Arab Journal for Talent Development, 3(5): 83-107 